\title{
Constructing a New Engineering Training Model Oriented on Advanced Manufacturing Engineering
}

\author{
Liu Xiang ${ }^{1,2}$ \\ ${ }^{1}$ Engineering Training Centre, Wuhan University of Science \\ and Technology, \\ ${ }^{2}$ School of Machinery and Automation, Wuhan University of \\ Science and Technology,
}

\author{
Xia Xuhui*, Wang Lei \\ School of Machinery and Automation, Wuhan University of \\ Science and Technology, 430081
}

\author{
Cao Jianhua ${ }^{1,2}$ \\ 1. Engineering Training Centre, Wuhan University of Science and Technology, 430065 \\ 2. School of Machinery and Automation, Wuhan University of Science and Technology, 430081
}

\begin{abstract}
The combination of advanced manufacturing technology and engineering education puts forward higher requirements for engineering training courses. Aiming at the problems exposed in engineering training courses, a new training mode of advanced manufacturing engineering was put forward, which is guided by the idea of outcome-oriented and carries on the advanced manufacturing technology. At last, the construction of the new model is discussed from the aspects of curriculum system, evaluation method and cloud platform construction.
\end{abstract}

Keywords-advanced manufacturing; engineering training; outcome orientation; engineering education; education reform

\section{INTRODUCTION}

The world economy has gradually changed from industrial economy to information economy. New technologies, new industries, new formats and new models represented by "Internet +", advanced manufacturing and intelligent manufacturing are becoming the development engines of the new economic era [1-3]. The core driving force of today's social development has gradually changed from "power-driven" to "technology-driven". The relationship among economy, science and technology and engineering education is getting closer and closer, and they are interdependent and promote together. The progress of science and technology will inevitably have a great impact on engineering education. In order to support the rapid development of the new economy and meet the industry's demand for innovative technical talents, China's engineering education must be highly coupled with the national economic and social development, and change from service adaptation to support-led transformation, which is an important mission entrusted to engineering training in the new era.

At present, the scale of Higher Engineering Education in China ranks first in the world. With the increasing investment of the state and governments at all levels in higher education, domestic universities have made great progress in the construction of software and hardware. However, there is still a big gap between the construction of University connotation and the understanding of undergraduate education and the well-known international universities [4-5]. In June 2016, China formally joined the Washington Agreement on
International Engineering Education, which symbolizes that China's colleges and universities fully accept "outcomes-oriented" as the theoretical guidance of domestic engineering education [6-8]. Therefore, guided by the concept of outcomes-oriented, exploring and constructing a new training mode of advanced manufacturing engineering will be a new subject that engineering training urgently needs to face, and also a new requirement for deepening the reform of current training mode, teaching means and teaching content.

\section{PROBLEMS EXISTED AND THOUGHTS OF REFORM}

Engineering training is a practical teaching content with the largest teaching scale and the largest number of students in engineering education. Engineering training center is the bridge between university talent training and national industrial demand, and the main training practice platform for training national innovative talents. But in our long-term teaching practice, engineering training has exposed the following problems:

\section{A. Engineering practice teaching system lags behind industrial development}

The traditional engineering training teaching mode aims at simple training, simple cognition and simple simulation production, which is out of touch with the national industrial development and the demand for innovative talents. Some courses are obsolete and slow to update. Some courses from 20 to 30 years ago are insufficient to meet the needs of high and new technology industries, such as intelligent manufacturing, added material manufacturing, Internet plus, Internet of things, and new material applications.

\section{B. Single curriculum form and insufficient integration with modern technological means}

The course form is scattered, the skill training is independent, the practice content and result are fixed, and the operation steps are programmed, so students can not form the habit of thinking independently in the training. Forming a learning mode of "emphasizing imitation, thinking less, single item and whole", students lack innovation space in the process of participation. Answer-style practice lacks the content of cultivating students' individuality and creativity. 


\section{The self-examination orientation of engineering training course is not clear}

For a long time, thinking habits have been solidified as engineering training is only an experimental course, which serves the basic courses of mechanical processing and manufacturing. But not aware of the role of engineering training in cultivating students' independent personality and innovative ability. To a great extent, this orientation and thinking habits restrict the construction and development of engineering training courses.

In view of the problems exposed in current engineering training, it is necessary to integrate innovation and entrepreneurship education into the whole process of engineering training from the perspective of serving the national strategy, satisfying the industrial needs and facing the future development, and form a multi-synergistic engineering training and education system with students as the center and results as the guidance. Do a good job of top-level design of engineering training teaching, build a platform related to multi-disciplinary cross-cutting and strategic emerging industries, integrate discrete engineering training units organically, form high-quality engineering training projects, avoid the problems of old training content and inadequate innovative training. Specifically, it can be explored in the following directions:
1) Construction of engineering training model based on "four steps + two teams"

According to the law and development trend of modern manufacturing technology, a new teaching mode of "four steps + two teams" for engineering training based on OBE is constructed with advanced manufacturing training project as the carrier. That is, according to the four-step thinking of "learning achievement orientation - module division - problem orientation, task-driven - learning output", the implementation path is the organic combination of teaching and learning of the two teams of "interdisciplinary engineering training team" and "student autonomous learning team" (as shown in Figure 1). Further exploration of step-by-step implementation strategies and methods, such as allowing students to form cohesive learning practice innovation team, independent selection of instructors, teachers to adjust teaching arrangements according to needs, students to adjust learning strategies, self-management of engineering training practice. Enabling students to participate in the actual project of advanced manufacturing and emphasizing the status of student center can not only arouse the enthusiasm of students in engineering training and broaden their horizons, but also effectively guarantee the output of students' engineering training results.

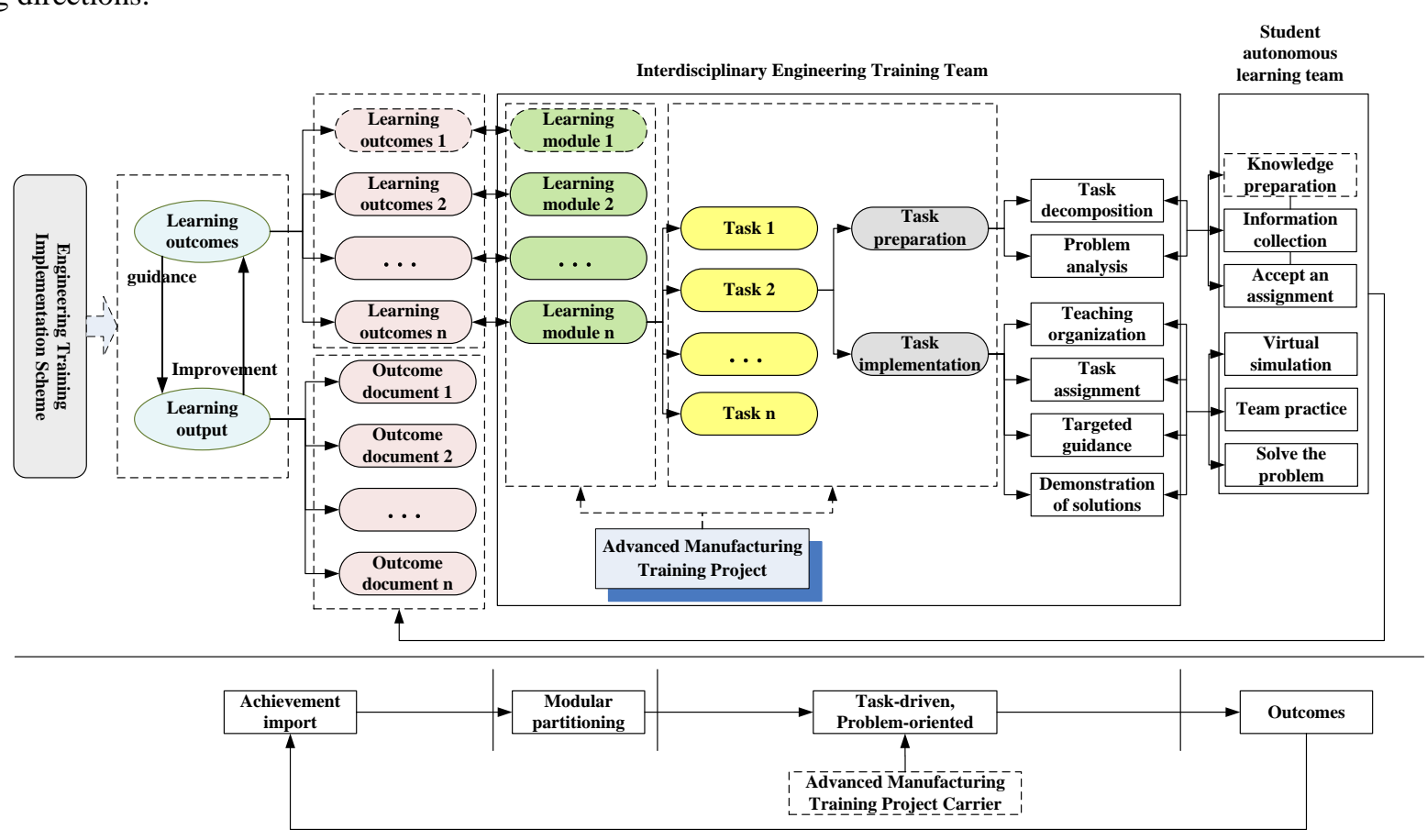

Fig. 1 Engineering Training Model of "Four Steps + Two Teams"

2) Exploring the establishment of multi-level and gradual advanced manufacturing engineering training course system

Based on advanced manufacturing technology and intelligent manufacturing technology, a multi-level progressive advanced manufacturing engineering training curriculum system is established through new concepts, new models and new means (as shown in Figure 2). The educational characteristics of advanced manufacturing engineering training are reflected from teaching tasks, teaching process and teaching results. Its core purpose is to take students as the main body, increase students' participation in the curriculum, mobilize students' enthusiasm, and carry out practical training which is challenging, exploratory and innovative. In teaching, modern scientific and technological means embodying advanced manufacturing technology are integrated, and some 
new courses in line with the direction of industrial

development are added to broaden students' horizons

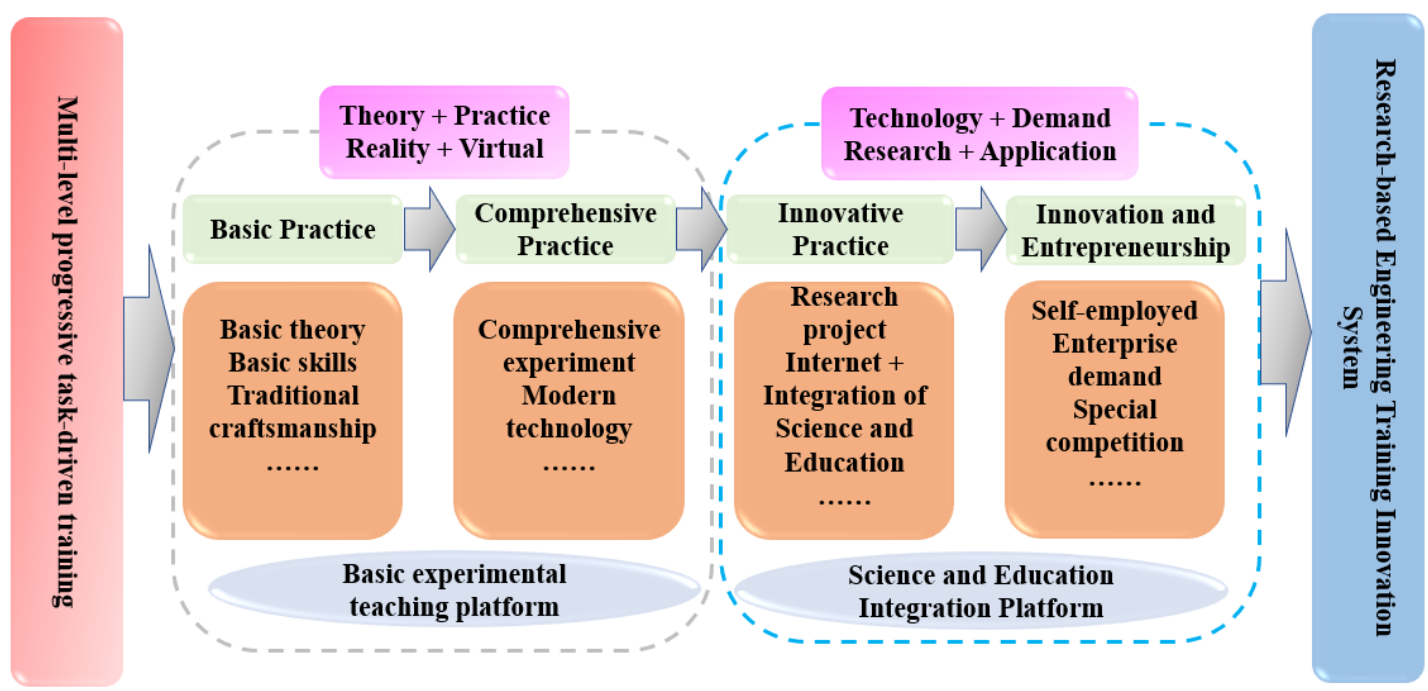

Fig. 2 Engineering Multi-level and Gradual Advanced Manufacturing Engineering Training Course System and Training Innovation System

3) Establishment of achievement-oriented evaluation methods for engineering training

According to the relevant professional training plan and graduation requirements, combined with the practical and innovative ability needs of engineering and technical personnel in industries and enterprises, the evaluation system and methods of engineering training teaching based on OBE are studied and formulated, as shown in Figure 3. To study the quality assurance system of engineering training teaching based on OBE, it is necessary to continuously monitor and evaluate the quality of Engineering Training Teaching under the new mode, collect the results of students' stage engineering training and analyze the data in the process of evaluation, find out the existing problems, and in the future project. It should be solved in the practice of training and teaching.

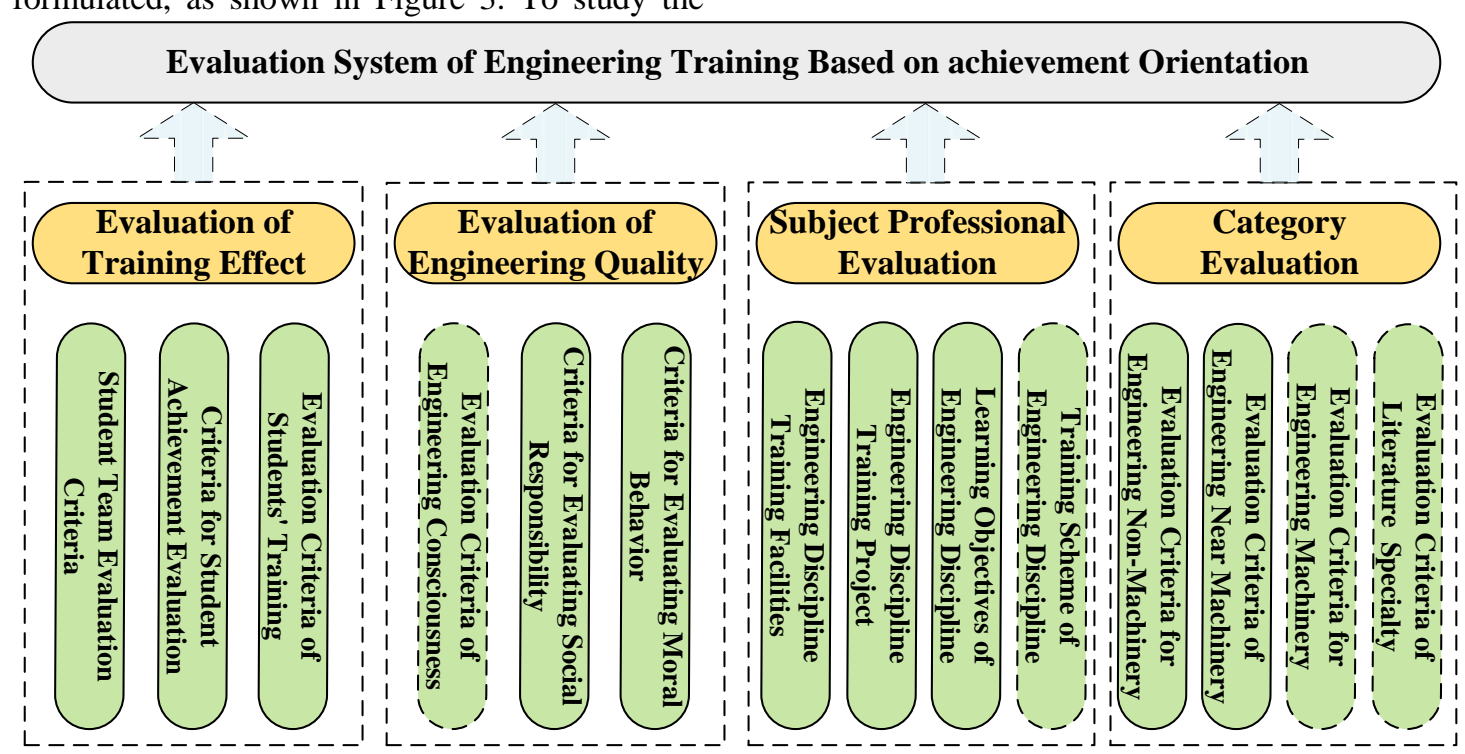

Fig. 3 Evaluation System of Engineering Training Based on OBE

4) Resources construction of engineering training cloud platform

Explore modern educational methods and means such as information technology, network technology and virtual simulation technology, and establish and develop advanced manufacturing engineering training cloud teaching platform which highlights the combination of virtual and real, space-time and online and offline, as shown in Figure 4.
According to the requirement of advanced manufacturing such as intelligent manufacturing, according to the idea of "taking machinery as the core, material as the basis and information control as the means", the traditional engineering training projects are reformed and more engineering training projects in the direction of advanced manufacturing technology are developed. Relying on the existing training resources in the school, introducing advanced manufacturing equipment and 
engineers and technicians of enterprises, exploring the mode of engineering training education through School-enterprise
Cooperation and international cooperation, and jointly carrying out personnel training in engineering training links.

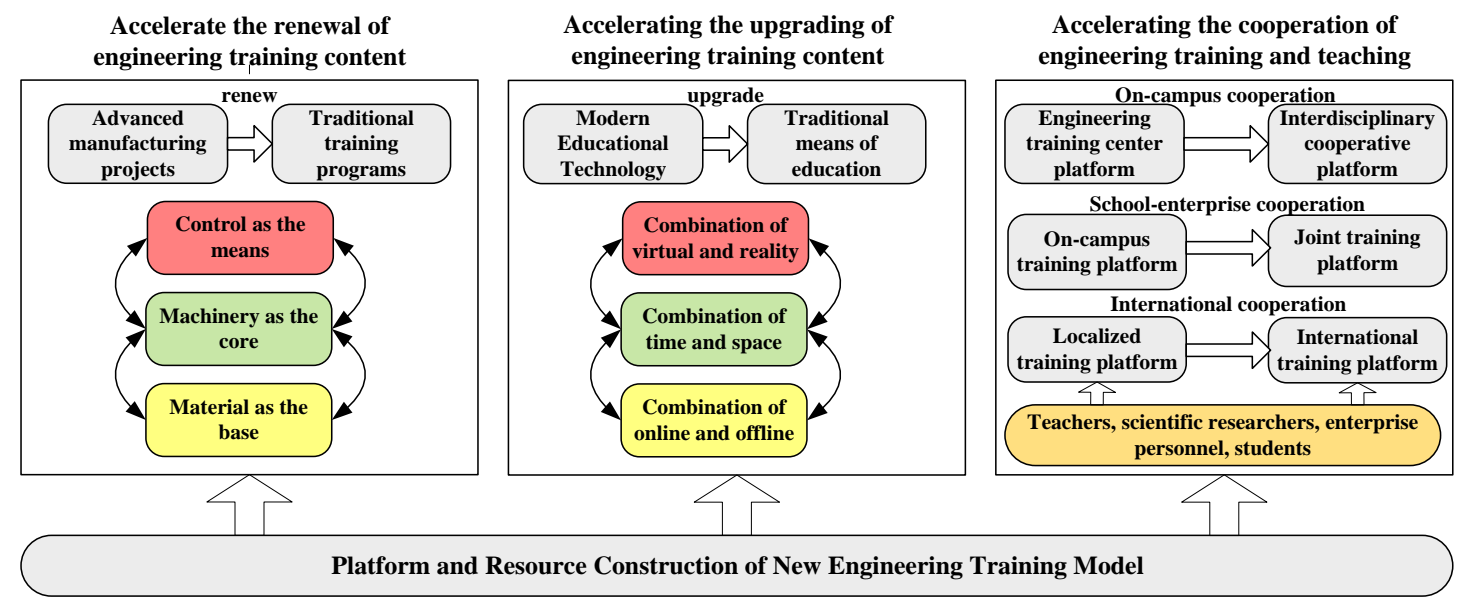

Fig. 4 Resource Construction of Engineering Training Cloud Platform

\section{CONCLUSION}

With the rapid development of advanced manufacturing technology, the concept of manufacturing is continuously extended, and the concept of large-scale manufacturing or large-scale engineering covering the whole life cycle of products such as research, development, design, manufacturing, management, marketing and service has gradually been formed. According to this idea, enterprises and society put forward higher requirements for engineering and technical personnel trained in Colleges and universities, that is, they should have the ability to collect and process information extensively, acquire new knowledge continuously, analyze and solve practical problems on the basis of mastering solid natural science knowledge and broad knowledge of Humanities and social sciences, question ability, organization and management ability, collaborative communication ability and social activity ability. Introducing some key technologies of industry-oriented advanced manufacturing into engineering training teaching, guided by the concept of results-oriented education, constructing a new engineering training mode consistent with the direction of industrial development, and cultivating students' ability to solve complex engineering problems and innovative consciousness are the main characteristics of the future development of engineering training courses.

\section{ACKNOWLEDGEMENT}

This research was financially supported by the Hubei Province Higher Education Teaching Research Project (2018254, 2018252); Wuhan University of Science and Technology Teaching and Research Project (2017X062,2018Z004,2018X07,Yjg201801,2018X072,2019X 085,2019Z005).

\section{REFERENCES}

[1] Zhang Ge, ZHANG Xuejun, ZHU Yuping, etc. Exploration on construction of engineering training center under background of intelligent manufacturing $[\mathrm{J}]$. Experimental Technology and Management, 2017, 34(2): 209-213.

[2] YE Huichun, SHEN Lianguan. Research on engineering practical teaching under current advanced manufacturing technology[J]. Experimental Technology and Management, 2018,35(4): 37-40.

[3] ZHOU Ji. Intelligent Manufacturing--Main Direction of "Made in China 2025' $[\mathrm{J}]$. China Mechanical Engineering, 2015, 26(17): 2273-2284

[4] WEI Xianggui, FU Shuigen, ZHANG Keyan, etc. Research and practice on strengthening three environmental constructions of engineering training center[J]. Experimental Technology and Management, 2018 , 35(10): 193-196

[5] LI Yongliang, XIA Hongjun. The Teaching Practice and Exploration of Advanced Manufacturing Technology in Engineering Training[J]. Education Teaching Forum, 2018, (31): 154-155.

[6] Evans K M, King J A . Research on OBE: What We Know and Don't Know[J]. Educational Leadership, 1994, 51(6):12-17.

[7] Barman L, Silén C, Bolander L K . Outcome based education enacted: teachers' tensions in balancing between student learning and bureaucracy $[\mathrm{J}]$. Advances in Health Sciences Education, 2014, 19(5):629-643.

[8] Deneen C, Brown G , Bond T, et al. Understanding outcome-based education changes in teacher education: Evaluation of a new instrument with preliminary findings[J]. Asia-Pacific Journal of Teacher Education, 2013, 41(4):441-456. 